\title{
Pharmacotherapeutic study of efficacy, safety and prognostic analysis of anti snake venom serum in snake bite patients
}

\author{
Khalid Inamdar*, Sudhakar M. Parhate, Rahul D. Randad
}

Department of Pharmacology, Government Medical College and Hospital, Akola

Maharashtra, India

Received: 26 January 2017 Accepted: 27 February 2017

*Correspondence to:

Dr. Khalid Inamdar,

Email:

kikhalidinamdar@gmail.com

Copyright: (C) the author(s), publisher and licensee Medip Academy. This is an openaccess article distributed under the terms of the Creative Commons Attribution NonCommercial License, which permits unrestricted noncommercial use, distribution, and reproduction in any medium, provided the original work is properly cited.

\begin{abstract}
Background: Snakebite is a common medical emergency especially in the rural areas. The effective measure to treat most of the manifestations of venomous snake bite is timely administration of anti-snake venom serum (ASVS). Problems associated with ASVS use are lack of evidence for optimal dose schedule and occurrence of hypersensitivity reactions.

Methods: A retrospective review of snakebite cases was carried out from record section of a tertiary care teaching hospital from January 2011 to December 2011.

Results: Out of total 202 snakebite patients admitted during the study period, age group of 21-30 years (mainly male victims) accounted for highest no. of snakebite cases $(25.7 \%)$. The mean $( \pm$ SD) dose of ASVS used was $124( \pm 112)$ $\mathrm{mL} .11 .8 \%$ patients had suffered from adverse drug reactions due to ASVS. $7.4 \%$ patients required mechanical ventilation. Overall mortality in our study was $9.4 \%$. Mortality was higher $(50 \%)$ where the time interval between the snakebite and initiation of treatment was $>6$ hours. Out of total 15 patients who required mechanical ventilation, $\mathrm{n}=10(66.6 \%)$ patient died.

Conclusions: In our study, mean dose of ASVS used was as per WHO guidelines. Less incidence of adverse drug reaction due to ASVS may be because of co-administration of corticosteroids and anti-histaminics. Delay in getting treatment with ASVS, neurotoxic envenomation and respiratory failure, were the risk factors associated with adverse prognosis due to snake bite in our set up.
\end{abstract}

Keywords: Adverse drug reaction, Anti snake venom serum, Dose, Prognosis

\section{INTRODUCTION}

Snake bite is a common medical emergency and an occupational health hazard especially in the rural population. ${ }^{1}$ It has been estimated that 5 million snake bite cases occur worldwide every year, causing about 100,000 deaths.

In India, an estimated 200,000 persons per year fall prey to snake bite, with an estimated annual fatality rate of $35,000-50,000 .^{2}$ The true burden of morbidity and mortality from snake bites is not known. The Registrar General of India's "Million Death Study" indicated that in 2005, snake bites caused 45,900 deaths in India. ${ }^{3}$ In Maharashtra, an estimated 10,000 annual venomous snake bites accounts for 2000 deaths. ${ }^{4}$ The main cause of this "unacceptable incidence" of snake bite fatalities is that people try all kinds of "bizarre remedies" initially, instead of going to the nearest hospital. ${ }^{5}$ It has been reported that in most developing countries, up to $80 \%$ of individuals bitten by snakes first consult traditional practitioners before approaching a medical centre. ${ }^{6,7}$

Of more than 3000 known species of snakes, only about 300 are venomous and in India there are about 216 identifiable species of snakes, of which 52 are known to be poisonous. ${ }^{8}$ The most important snakes in India belong to the families Elapidae, Viperidae and Hydrophiidae. ${ }^{9}$

The effective measure to treat most of the manifestations of venomous snake bite is the timely administration of anti-snake venom serum (ASVS). In India, polyvalent 
anti snake venom serum (ASVS) raised in horses using venoms of four important venomous snakes viz. Indian cobra (Naja naja), Indian krait (Bangarus caeruleus), Russell's viper (Daboia russelii) and saw scaled viper (Echis carinatus) is widely used in the management of snake bites.

Though ASVS is the mainstay of therapy for snake bite patients, there is no universally accepted standard regimen regarding the optimum dose, frequency of administration and duration of therapy. The hitch with determining the optimum ASVS dose is that the quantity of venom injected at a bite is variable, depending on the species and size of the snake, the mechanical efficiency of the bite, whether one or two fangs penetrated the skin and whether there were repeated strikes. ${ }^{10}$

Besides, other problems associated with ASVS use are the occurrence of hypersensitivity reactions (ASVS being an animal serum product), limited availability and possibility of inappropriate use. ${ }^{11}$

With this background, we planned the present study with the objective of assessing ASVS use, adverse reactions to ASVS and outcome in snake bite patients. We have also analyzed the risk factors associated with mortality from snake bite.

\section{METHODS}

The present study was a retrospective observational study. The study was conducted at a tertiary care teaching hospital.

\section{Study subjects and study period}

All indoor patients of snake bite with documented use of ASVS during the period of January 2011 to December 2011 were included in the study. Cases of unknown bite and the patients whose hospital records were missing or grossly inadequate were excluded from the study.

\section{Method of data collection}

The medical records of snake bite patients during the study period were reviewed to extract information regarding demographics (Age, Gender, Hospital registration No., Date of admission and address), Site of bite, Time of bite, Time elapsed between bite to get target treatment (ASVS), Clinical features, local findings, details of ASVS administration (Total dose and number of vials used), concomitant drugs used, occurrence of adverse reactions to ASVS, need of assisted ventilation, duration of hospital stay, and clinical outcome. Laboratory investigations such as haemogram (Haemoglobin level, Total leucocyte count, Platelet count), Blood urea nitrogen (BUN), serum creatinine, urine microscopy were also recorded.
This information was then entered in a predesigned proforma. Data of total 202 snake bite patients was analyzed.

\section{Statistical analysis}

Data were entered in Microsoft excel sheets. Statistical analysis was done using statistical software SPSS for windows, version 20.0.

Proportions and percentages were obtained. While mean \pm standard deviation (SD) was applied for the continuous variables, proportions were applied for the categorical variables. Chi-square test (Fischer's exact test for small numbers) was used to find out the significance of difference between two variables. $P \quad<0.05$ was considered a statistically significant difference.

\section{RESULTS}

A total number of 202 patients with snake bites were reviewed for analysis.

The predominant victims of snake bite were males $n=124$ (61.4\%).

The mean $( \pm$ SD) age was $34.04( \pm 16.6)$ years. Age group of 21-30 years accounted for highest number of snakebite cases $n=52(25.7 \%)$. Highest incidence of snakebite was found in the month of October $[n=35(17.3 \%)]$.

Table 1: Demographic and other characteristics of snake bite patients.

\begin{tabular}{|ll|}
\hline Variables & \multicolumn{1}{l|}{ Value } \\
\hline Gender & $124(61.4 \%)$ \\
\hline Male & $78(38.6 \%)$ \\
\hline Female & \\
\hline Age (Yrs) & $34.04( \pm 16.60)$ \\
\hline Mean $( \pm$ SD) & $3-75$ \\
\hline Range & \\
\hline Rural and urban prevalence & $169(83.7 \%)$ \\
\hline Rural & $33(16.3 \%)$ \\
\hline Urban & $124(61.4 \%)$ \\
\hline Time of bite & $78(38.6 \%)$ \\
\hline 6 AM-6 PM & \\
\hline 6 PM-6 AM & $115(56.93 \%)$ \\
\hline Anatomical site of bite & $79(39.10 \%)$ \\
\hline Lower limbs & $06(2.97 \%)$ \\
\hline Upper limbs & $02(0.99 \%)$ \\
\hline HNF & $1.90( \pm 1.97)$ \\
\hline Back & $0.16-18$ \\
\hline Time elapsed between bite to receive ASVS (Hours) \\
\hline Mean $( \pm$ SD) & \\
\hline Range & \\
\hline
\end{tabular}

Value expressed as $\mathrm{n}(\%)$ or mean $( \pm \mathrm{SD})$

$\mathrm{HNF}=\mathrm{Head}$, Neck and Face, $\mathrm{SD}=$ Standard Deviation, ASVS=

Anti snake venom serum 
A majority of victims $n=169(83.7 \%)$ were from the rural areas, Most of the bites $n=124(61.4 \%)$ occurred during the day time (6 AM-6 PM), Snake bites were recorded mainly on the lower limbs, $n=115(57 \%)$. Mean $( \pm$ SD) time elapsed between bite to receive ASVS was 1.90 $( \pm 1.97)$ hours (Table 1$)$.

The most common presenting symptom of snake bite was vomiting $\mathrm{n}=27(21 \%)$, as far as local findings and clinical signs were concerned, fang marks were present in, $n=69$ $(41.1 \%)$, Ptosis was present in $n=46(27.4 \%)$ patients.

Mean $( \pm$ SD) dose of ASVS used was $124.4( \pm 112.0) \mathrm{mL}$. In majority $n=80(39.6 \%)$ of snake bite patients total dose of ASVS used was in the range of 50-100 mL (Figure 1).

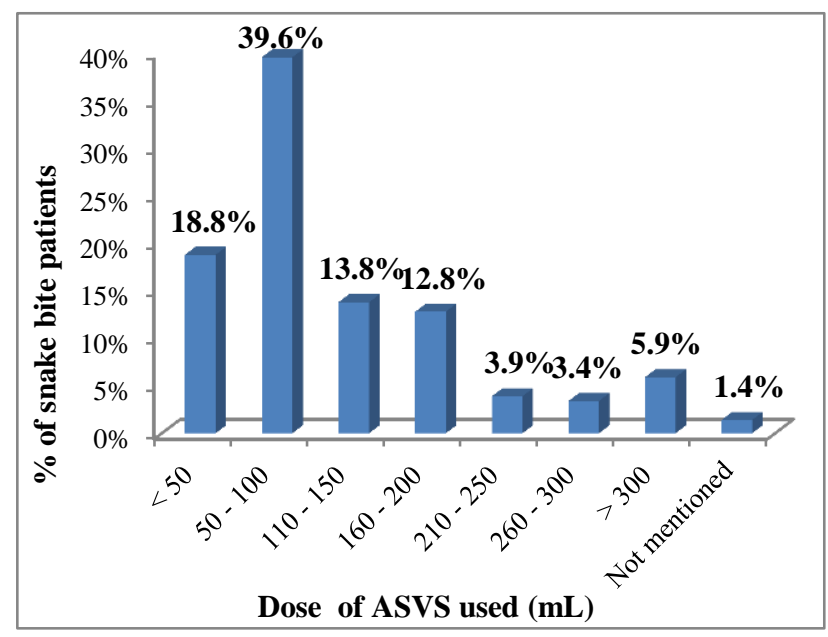

Figure 1: Dose of ASVS used.

Out of total 202 patients, $n=24$ (11.8\%) developed adverse drug reactions after ASVS administration. Itching $\mathrm{n}=8(33 \%)$ was the most common adverse drug reaction, followed by maculopapular rash $n=7$ (29\%) (Figure 2). Corticosteroids (Hydrocortisone, Dexamethasone and Prednisolone) alone and few in combination with antihistaminics (Chlorpheniramine) were used in, $\mathrm{n}=55$ $(27.2 \%)$ patients.

The other drugs given concomitantly with ASVS were Neostigmine $n=83(41 \%)$.

Ranitidine $n=81 \quad$ (40\%), Cefotaxime $n=67 \quad(33 \%)$, Corticosteroids $n=55(27 \%)$ and Chlorpheniramine $n=33$ (16\%). $n=15 \quad(7.4 \%)$ patients required mechanical ventilation. Mean $( \pm$ SD) duration of hospital stay was 3.1 ( \pm 2.25$)$ days. Majority $n=172(85.1 \%)$ of snake bite patients made good recovery; mortality was found in, $\mathrm{n}=19(9.4 \%)$ of cases, and $\mathrm{n}=11(5.4 \%)$ patients were discharged against medical advice. Mortality was higher $(50 \%)$ where the time interval between the snakebite and initiation of treatment was $>6$ hours, while it was less $(8.3 \%)$ where treatment occurred within 2 hours. These findings were statistically significant (Pearson chisquare=7.961, $\mathrm{P}=0.019$ ).

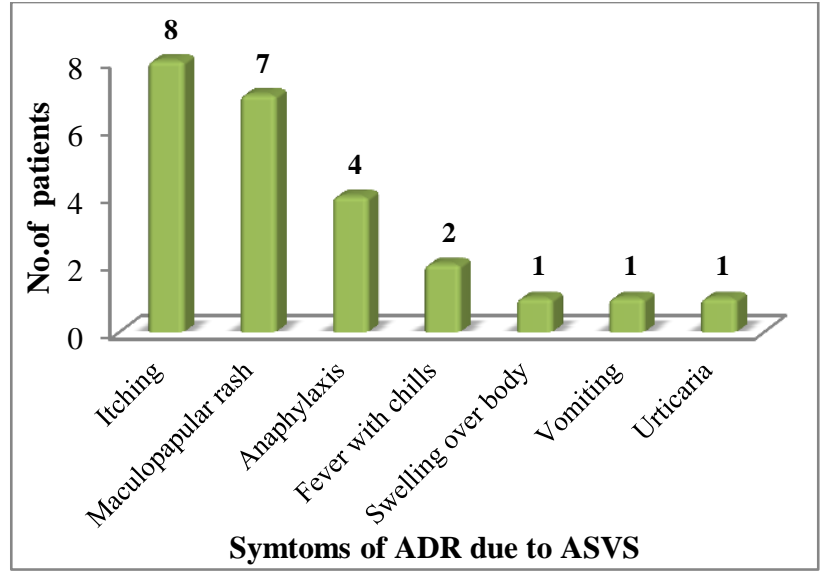

Figure 2: Adverse ASVS reactions.

Mortality was also higher in patients who were bitten over head, neck and face (33\%), as compared to those bitten over upper limbs $(7.59 \%)$ and lower limbs $(9.56 \%)$, but these findings were not statistically significant.(Pearson Chi-square $=6.996, \mathrm{p}=0.072$ ). Out of total 15 patients who required mechanical ventilation, $\mathrm{n}=10(66.6 \%)$ patient died.

Mortality was less $(4.8 \%)$ in patients who did not require assisted ventilation $(n=187)$, thus demonstrating statistical significance in mortality in relationship with assisted ventilation (Pearson Chi-square $=62.347, \mathrm{p}=0.000$ ). Snake could be identified in only 20 cases [Vasculotoxic $n=13$ $(65 \%)$, Neurotoxic $n=7(35 \%)]$. Mortality was higher in neurotoxic envenomation $(85.7 \%)$ as compared to vasculotoxic envenomation (15.3\%) with statistically significant difference. (Fisher's Exact test=9.377, p=0.04) (Table 2).

\section{DISCUSSION}

In present study, 202 patients of snake bite were recorded from January-December 2011 period. Bites were more frequent in males than females, the ratio being approximately 1.6:1, Others have reported similar observations. ${ }^{12,13}$ Snakebite was most common $(25.7 \%$ ) in the age group of 21-30 year. In most of the studies it was found that majority of the snake bite victims were young adult males in second to fourth decades of life. ${ }^{3,14,15}$ The predominance of male gender in present study put them at increased risk because of their involvement in outdoor activities, findings similar to previous studies. ${ }^{16-18}$

In present study, majority of the snake bites involved the lower extremities $(57 \%)$, it can be explained by the fact that most of the time, the snakes are trodden upon by the victims. ${ }^{19-21}$ Also, many other outfield activities including fishing, plantation, wood collection or tending crops or gardens where fairly a large number of people walk barefooted, particularly in rural areas, there is increased risk of snake bite. 
Table 2: Risk factors associated with mortality in snake bite patients.

\begin{tabular}{|c|c|c|c|c|}
\hline Variables & Discharged & Died & Total & p value \\
\hline \multicolumn{5}{|c|}{ Time elapsed between bite } \\
\hline$<2 \mathrm{Hrs}$ & $142(70.2 \%)$ & $13(6.4 \%)$ & $155(76.7 \%)$ & \multirow{4}{*}{$0.019^{*}$} \\
\hline 2-6 Hrs & $39(19.3 \%)$ & $04(1.9 \%)$ & $43(21.2 \%)$ & \\
\hline$>6 \mathrm{Hrs}$ & $02(0.9 \%)$ & $02(0.9 \%)$ & $04(1.9 \%)$ & \\
\hline Total & $183(90.5 \%)$ & $19(9.4 \%)$ & $202(100 \%)$ & \\
\hline \multicolumn{5}{|l|}{ Site of bites } \\
\hline Lower limbs & 104(51.4\%) & $11(5.4 \%)$ & $115(56.9 \%)$ & \multirow{5}{*}{0.072} \\
\hline Upper limbs & $73(36.1 \%)$ & $06(2.9 \%)$ & $79(39.1 \%)$ & \\
\hline HNF & $04(1.9 \%)$ & $02(0.9 \%)$ & $06(2.9 \%)$ & \\
\hline Back & $02(0.9 \%)$ & $00(0.0 \%)$ & $02(0.9 \%)$ & \\
\hline Total & $183(90.5 \%)$ & $18(9.4 \%)$ & $202(100 \%)$ & \\
\hline \multicolumn{5}{|c|}{ Mechanical Ventilation } \\
\hline Yes & $05(2.4 \%)$ & $10(4.9 \%)$ & $15(7.4 \%)$ & \multirow{3}{*}{$0.000^{*}$} \\
\hline No & $178(88.1 \%)$ & $09(4.4 \%)$ & $187(92.5 \%)$ & \\
\hline Total & $183(90.5 \%)$ & $19(9.4 \%)$ & $202(100 \%)$ & \\
\hline \multicolumn{5}{|c|}{ Type of envenomation ${ }^{\#}$} \\
\hline Neurotoxic & $01(5.0 \%)$ & $06(30.0 \%)$ & $07(35.0 \%)$ & \multirow{3}{*}{$0.004 *$} \\
\hline Vasuculotoxic & $11(55.0 \%)$ & $02(10.0 \%)$ & $13(65.0 \%)$ & \\
\hline Total & $12(60.0 \%)$ & $08(40.0 \%)$ & $20(100 \%)$ & \\
\hline
\end{tabular}

value expressed as n (\%), Hrs $=$ Hours, $\mathrm{HNF}=\mathrm{Head}$, neck \& face

$* \mathrm{p}<0.05$, \#snake could be identified in 20 cases only

Incidence of snake bite in present study was more during day time $(61.4 \%)$, this can be explained on the basis of increased outdoor activity during daytime which increases possibility of encounter with snakes and hence snake bites. Kulkarni et al. reported that $68.2 \%$ cases were bitten during day. ${ }^{22}$ However Sharma et al, found that $60.6 \%$ bite occurred during night. ${ }^{23}$

The higher incidence of snake bite in rural areas in this study $(83.7 \%)$ can be because of large number of people working in fields in rural areas e.g., paddy fields and habit of walking barefoot. ${ }^{24}$ Their houses which are built of mud, provide access and shelter to snakes. ${ }^{25}$ Sleeping on the floor and outside the house or in farms may also be responsible for increased number of cases in rural areas. Kulkarni et al, found that $90 \%$ bites were from rural areas. $^{22}$ Naik et al, reported that $83.6 \%$ were from rural areas. ${ }^{26}$ Sharma et al, found a rural: Urban ratio of $4.7: 1$, same was 5.1:1 in present study. ${ }^{23}$

Increase in snake bite cases is mainly seen during the monsoon season when there is rainfall and increase in harvesting activities. ${ }^{23,25,27}$ Because of the heavy rains, the holes and burrows are filled up with water and snakes come out of it and number of encounters of men with snakes increases, increasing the incidence of snake bites cases. The breeding habits of preys like frogs also follow the monsoon. ${ }^{28}$ Naik et al, reported that $60.6 \%$ cases occurred between June to November. ${ }^{26}$ Hansdak et al, reported that $51 \%$ cases occurred during monsoon
(August-October). ${ }^{29}$ In present study the bite incidence was maximum in October (17.3\%).

Vomiting was the presenting feature in maximum patients $(21 \%)$ due to autonomic effect. Haematological, cardiovascular and neuroparalytic signs were also noted.

The total dose of ASVS administered in our patients ranged from 0 to $710 \mathrm{~mL}$ with a mean $( \pm \mathrm{SD})$ dose of 124 $( \pm 112) \mathrm{mL}$. Majority of the snake bite patients, who were give intravenous ASVS received in the dose of 50 -100 $\mathrm{mL}$. The mean ASVS dose was within the recommended range, similar to the study done by Ahmed et al. ${ }^{19}$ Although ASVS has been used for many years, there is no universal consensus in many countries on the optimal dose and protocol of its administration. However, studies have shown that outcomes of treatment are comparable in patients receiving both high dose and low dose of ASV. Furthermore low dose is cost effective and associated with lesser degree of adverse effects. ${ }^{30}$

Adverse drug reaction in present study occurred in $11.8 \%$ of those who received ASVS, a finding similar to that reported by others. ${ }^{12,31}$ The ADRs so found includes gastrointestinal, cutaneous, cardiovascular, respiratory, renal and neurological. Hydrocortisone with or without chlorpheniramine maleate was used in, $25.2 \%$ patients in this study. Gawarammana et al. have shown the efficacy of combination of chlorpheniramine and hydrocortisone in reduction of anti-snake venom serum reactions. ${ }^{32}$ 
In present study we found that prolonged bite to hospital time period i.e., delayed arrival to hospital was associated with high mortality. Most of the studies have observed the correlation between bite to hospital time and complications or mortality. ${ }^{15,23,33}$ This can be explained by the fact that incidence of complications is directly proportional to the duration of venom in the blood prior to its neutralization by ASVS due to late arrival of patient at hospital and as complications occur mortality will increase. $^{15}$

In hospital based studies, mortality rates ranged from $3 \%$ to $20 \%$. Various authors have found important contributors to death in such patients like delay in arrival at hospital (prolonged bite to hospital time) respiratory failure (requiring mechanical ventilation), bite over proximal parts of body i.e. head and neck and neurotoxic type of snake bite finding similar to present study. $4,9,12,15,27,32$

Sharma et al. observed that the rate of death in a specialty hospital equipped with anti-snake venom serum, ventilators and dialysis facilities is much lower than rural hospitals, which lack these (facilities). ${ }^{23}$ Most of the victims seek treatment by traditional healers before they present to the hospital and many die before they can find transport to reach the nearest hospital. ${ }^{34}$ Victims of snake bite die because they do not receive anti-snake venom serum, receive it too late or receive too little. ${ }^{35}$ The number of patients in this study who received ASVS therapy within $6 \mathrm{hrs}$ were $98 \%$, which appear justified, since few patients even though not practically bitten seek medical aid.

Apart from ASVS, Oxygen therapy and tetanus toxoid (TT) to all patients, some were given neostigmine (41\%) on sign of respiratory failure, Ranitidine (40\%) for gastritis, Cefotaxime $(33.3 \%)$ in view of microbial infection, Corticosteroids $(27.2 \%)$ for anti-immune effect and chlorpheniramine maleate $(16 \%)$ for anti-histaminic effect. Overall the pharmacotherapy appears scientifically justified.

Few $(7.4 \%)$ patients needed ventilation for respiratory paralysis. Satisfactory recovery was observed in $85.1 \%$ patients whereas mortality rate was $9.4 \%$. On admission 7 subjects were brought in altered sensorium state out of which $n=2(28.6 \%)$ succumbed to death which suggest irreversible death prone neurological damage.

ASVS is the only specific and targeted therapy for snake bite victims. In patients who arrived later than 6 hours of bite, mortality was higher $(50 \%)$ indicating need of early specific and co-therapy. As far as site of bite is considered, the bite over HNF, mortality was found at the top $(33 \%)$, this finding may be attributed to rapid neurological access of snake venom. Mortality rate due to cobra bite was $85.7 \%$ whereas to viper bite was $15.3 \%$, indicate death prone toxicity of former venom. Mortality rate in patients subjected to ventilators was $66.6 \%$.
Anaphylaxis was the life threatening adverse effect of ASVS therapy $(16.6 \%)$ wherein the presenting features were profound hypotension, bronchospasm, laryngeal edema, rash and anaphylactic shock. However $n=1(4 \%)$ patient died, Epinephrine, hydrocortisone, oxygen inhalation, IV fluids, Chlorpheniramine maleate, cefotaxime could prevent mortality.

It has been recommended by the WHO that snake bite should be formally recognized as an important occupational disease and should be made a specific notifiable disease in all countries in the South East Asian Region. ${ }^{4}$ Awareness and knowledge regarding prevention, particularly among farmers and field workers, should be disseminated and they should be advised not to disturb snakes, not to walk bare footed, and use protective boots to use a torch while walking on footpaths at night, sleeping on a cot (rather than on the floor) and under bed nets. $^{34,36-38}$

Persistent underestimation of its true morbidity and mortality has made snakebite the most neglected of all the WHO's "neglected tropical diseases", strategies to address this neglect should include the improvement of anti-snake venom serum to meet the challenge of neutralizing large injected doses of venom without compromising patient safety. Production of higher potency anti-snake venoms will be required by modern proteomic and antivenomic methods. ${ }^{39}$

Oral administration of ASV may also become possible in near future. Entrapping multiple components of antisnake venom in alginate, an economic, biodegradable polymer have been shown to retain the functional property of the anti-snake venom even after intestinal absorption and suggest possibility of the development of an orally effective first aid against snake envenomation, thereby increasing chances of survival of the victim. ${ }^{40}$

\section{CONCLUSION}

In conclusion, present study reveals that the mean dose of ASVS used in our hospital was as per the WHO guidelines. Fewer incidences of adverse drug reactions due to ASVS in this study may be because of coadministration of corticosteroids and antihistaminics. Delay in getting prompt treatment with ASVS, snake bite in proximal parts of the body especially in Head, neck and face (HNF), neurotoxic envenomation and respiratory failure requiring mechanical ventilation, were the risk factors associated with higher mortality (adverse prognosis) due to snake bite in our set up.

Funding: No funding sources

Conflict of interest: None declared

Ethical approval: The study was approved by the

Institutional Ethics Committee vide letter

No.0259/19/11/2014 


\section{REFERENCES}

1. Halesha BR, Harshavardhan L, Venkat KB. A study on the clinico-epidemiological profile and the outcome of snake bite victims in a tertiary care centre in southern India. J Clin Diagn Res. 2013;7(1):122-6

2. World Health Organization.Rabies and envenomings: A neglected public health issue. Geneva. WHO;2007.

3. Mohapatra B, Warrell DA, Suraweera W, Bhatia P, Dhingra N, Jotkar RM. Snakebite mortality in India: A nationally representative mortality survey. PLoS Negl Trop Dis. 2011;5:1018.

4. Warrell DA. Epidemiology of snake-bite in SouthEast Asia Region. In: Warrell DA (editor). Guidelines for the management of snakebite.New Delhi: WHO regional office for Southeast Asia. 2010;35-45.

5. Simpson ID, Norris RL. Snakes of Medical Importance in India: Is the Concept of the "Big 4" Still Relevant and Useful? Wilderness Environ Med. 2007;18:2-9.

6. Sharma SK, Chappuis F, Jha N, Bovier PA, Loutan L, Koirala S. Impact of snake bites and determinants of fatal outcomes in southeastern Nepal. The American journal of tropical medicine and hygiene. 2004;71(2):234-8.

7. Snow RW. The prevalence and morbidity of snake bite and treatment-seeking behaviour among a rural Kenyan population. Ann Trop Med Parasitol 1994;88:665-71.

8. Bawaskar HS, Bawaskar PH. Snake bite poisoning. Journal of Mahatma Gandhi Institute of Medical Sciences. 2015;20(1):5.

9. Bawaskar HS. Snake venoms and antivenoms: critical supply issues. J Assoc Physicians India. 2004;52:11-3.

10. Kumar BK, Nanda SS, Venkateshwarlu P, Kumar YK, Jadhav RT.Antisnake venom serum. Int J Pharm Biomed Res. 2010;1:76-89.

11. Pore SM, Ramanand SJ, Patil PT, Gore AD, Pawar MP, Gaidhankar SL, et al. A retrospective study of use of polyvalent anti-snake venom and risk factors for mortality from snake bite in a tertiary care setting. Indian J Pharmacol. 2015;47:270-4.

12. Punde DP. Management of snake-bite in rural Maharashtra: A 10-year experience. Nat Med J India 2005;18:71-5.

13. Brunda G, Sashidhar RB. Epidemiological profile of snake-bite cases from Andhra Pradesh using immunoanalytical approach. Indian $\mathrm{J}$ Med Res. 2007;125:661-8.

14. Meenatchisundaram S, Michael A. Snake bite and therapeutic measures: Indian scenario. Indian Journal of Science and Technology. 2009;2:69-73.

15. Narvencar K. Correlation between timing of ASV administration and complications in snake bites. J Assoc Physicians India. 2006;54:717-9.

16. Mulay D, Kulkarni V, Kulkarni S, Kulkarni N, Jaju R. Clinical profile of snakebites at SRTR Medical
College Hospital, Ambajogai (Maharashtra). Ind Medl Gaz. 1986;131:363-6.

17. Agrawal P, Aggarwal A, Gupta D, Behera D, Prabhakar S, Jindal S. Management of respiratory failure in severe neuroparalytic snake envenomation. Neurol India. 2001;49:25-8.

18. Anil A, Singh S, Bhalla A, Sharma N, Agarwal R, Simpson ID. Role of neostigmine and polyvalent antivenom in Indian common krait (Bungarus caeruleus) bite. J Infect Public Health. 2010;3:83-7.

19. Ahmed SM, Nadeem A, Islam MS, Agarwal S, Singh L. Retrospective analysis of snake victims in Northern India admitted in a tertiary level institute. J Anaesthesiol Clin Pharmacol. 2012;28:45-50.

20. Zulkifli A, Hashim M, Kharal Anuar A. Snake bites in kelantan, Peninsular Malaysia. Trop Biomed. 1995;12:1-4.

21. Jamaiah I, Rohela M, Ng T, Ch'ng KB, Teh YS, Nurulhuda AL, et al. Retrospective prevalence of snakebites from Hospital Kuala Lumpur (HKL)(1999-2003). Southeast Asian J Trop Med Public Health. 2006;37:200-5.

22. Kulkarni ML, Anees S. Snake venom poisoning, experience with 633 patients. Indian Paediatr. 1994;31:1239-43.

23. Sharma N, Chauhan S, Faruqi S, Bhat P, Varma S. Snake envenomation in a north Indian hospital. Emerg Med J. 2005;22:118-20.

24. Denker BM, Brenner BM. Azotemia and urinary abnormality. Harrison' s Principles of Internal Medicine. 2008; 17:271.

25. Kasturiratne A, Wickremasinghe AR, De Silva N, Gunawardena NK, Pathmeswaran A, Premaratna R, et al. The global burden of snakebite: A literature analysis and modelling based on regional estimates of envenoming and deaths. PLoS Med. 2008;5:218.

26. Naik RS, Tirpude BH, Khajuria BK. Mortality and morbidity patternin snake bite at MGIMS Sevagram, Wardha: A rural area. Indian Pract. 1997;50:31-5.

27. Patil VC, Patil HV, Patil A, Agrawal V. Clinical Profile and outcome of envenomous snake-bite at tertiary care centre in western Maharashtra. International Journal of Medicine and Public Health. 2011;1:28.

28. Reddy KS. Organic irritant poisons. In: Essentials of forensic medicine and toxicology. 27th ed. Hyderabad: Laxmi Printers; 2008;487-99.

29. Hansdak SG, Lallar KS, Pokharel P, Shyangwa P, Karki P, Koirala S.A clinico-epidemiological study of snake bite in Nepal. Trop Doct. 1998;28:223-6.

30. Kumar V, Gudge S, Mithare S, Mudbi S, Kulkarni S. a trial of low dose anti snake venom in the treatment of poisonous snake bites in brims teaching hospital, Bidar. Journal of Evolution of Medical and Dental Sciences. 1(3):8544-51.

31. Theakston RDG, Phillips RE, Warrell DA, Galagedera Y, Abeysekera DTDJ, Dissanayaka P, et al. Envenoming by the common krait (Bungarus caeruleus) and Sri Lankan cobra (Naja naja): Efficacy and complications of therapy with Haffkine 
antivenom.Trans R Soc Trop Med Hyg. 1990;84:3018.

32. Gawarammana IB, Kularatne SA, Dissanayake WP, Kumarasiri RP, Senanayake N, Ariyasena H. Parallel infusion of hydrocortisone \pm chlorpheniramine bolus injection to prevent acute adverse reactions to antivenom for snakebites. Med $\mathrm{J}$ Aust. 2004;180(1):20-3.

33. Suchithra N, Pappachan JM, Sujathan P. Snakebite envenoming in Kerala, South India: Clinical profile and factors involved in adverse outcomes. Emerg Med J. 2008;25:200-4.

34. Sharma SK, Koirala S, Dahal G ,Sah C. Clinicoepidemiological features of snakebite: a study from Eastern Nepal. Tropical Doctor. 2004;34:20-2.

35. Gold BS, Dart RC, Barish RA. Bites of venomous snakes. New England Journal of Medicine. 2002;347(5):347-56.

36. Sharma SK, Khanal B, Pokhrel P, Khan A, Koirala S. Snakebite-reappraisal of the situation in Eastern Nepal. Toxicon. 2003;41:285-9.

37. Pe T, Myint AA, Kyu KA, Toe MM. Acceptability study of protective boots among farmers of
Taungdwingyi Township. Myanmar Health Sciences Research Journal. 1998;10(2):57-60.

38. Bawaskar HS, Bawaskar PH. Profile of snakebite envenoming in western Maharashtra, India. Trans $\mathrm{R}$ Soc Trop Med Hyg. 2002;96:79-84.

39. Warrell DA, Gutiérrez JM, Calvete JJ, Williams D. New approaches and technologies of venomics to meet the challenge of human envenoming by snakebites in India. Indian J Med Res. 2013;138:3859.

40. Bhattacharya S, Chakraborty M, Mukhopadhyay P, Kundu PP, Mishra R. Viper and cobra venom neutralization by alginate coated multicomponent polyvalent antivenom administered by the oral route. PLoS Negl Trop Dis. 2014;8:3039.

Cite this article as: Inamdar K, Parhate SM, Randad RD. Pharmacotherapeutic study of efficacy, safety and prognostic analysis of anti snake venom serum in snake bite patients. Int $\mathrm{J}$ Basic Clin Pharmacol 2017;6:906-12. 